REVISTA ANDALUZA DE ANTROPOLOGÍA

NÚMERO 18: MIRADAS DESDE LA ANTROPOLOGÍA AMBIENTAL.

ABRIL DE 2020

ISSN 2174-6796

[pp. 153-171]

https://dx.doi.org/10.12795/RAA.2020.18.08

\title{
LA CALLE URBANA HECHA PASAJE COMERCIAL POPULAR. EL DRAMA COTIDIANO POR TRABAJAR
}

\author{
Felipe González Ortiz \\ Universidad Autónoma del Estado de México
}

\section{Resumen}

Este artículo hace visible, a través de la descripción de un caso, la forma como los comerciantes ambulantes dramatizan sus acciones sociales cotidianas. Se parte de reconocer que el capitalismo produce pobres que se ganan la vida, entre otras cosas, mediante el trabajo informal, apropiándose del espacio público, desde ahí se despliegan relaciones sociales que los involucran con actores administrativos, en las que el conflicto juega un papel estructurante. El valor del texto es el de hacer visible el drama de la acción cotidiana de la informalidad.

Palabras clave: informalidad, espacio urbano, sistema de relaciones, conflicto, ciudad.

\begin{abstract}
This article makes visible, through a case description, the way that street traders dramatize their daily social actions. It is based on recognizing that capitalism produces the poor who earn a living, among other things, through informal work, appropriating the public space, from where social relationship involved them with administrative actors. In this relationship the conflict plays a structuring role. The value of the text is to make visible the drama of daily action of informality.
\end{abstract}

Keywords: informality, urban space, relations system, conflict, city. 


\section{INTRODUCCIÓN}

En los espacios públicos de la ciudad que son apropiados por los comerciantes ambulantes, se construyen día a día, en actos teatralizados o performativos, los componentes de un sistema de relaciones sociales, integrando a actores en una malla de jerarquías que configuran los trazos generales del sistema institucional en su conjunto. Así, a partir de la informalidad se integran actores sociales - los comerciantes ambulantes, los consumidores esporádicos, los consumidores cautivos, el representante del Ayuntamiento, las autoridades del Ministerio Público, la persona que genera el permiso de palabra, el encargado del estacionamiento aledaño que guarda el puesto ambulante, el director de la escuela que da permisos de palabra, etcétera-, de cuyas vínculos cotidianos se configura un sistema de relaciones, con sus propias reglas y entendimientos singulares.

Las formas cómo las personas de bajos recursos se apropian del espacio urbano para construir las ocasiones para trabajar, representa un visor empírico, que permite construir los vínculos entre actores sociales como una red compleja de interdependencias; este vínculo se traduce en complicidades, entre actores, cuya meta es la administración pública de la calle, o la gobernabilidad de la misma.

Sitúo la observación empírica en una porción de una calle céntrica de la ciudad de Toluca, capital de la provincia de nombre Estado de México, a 60 kilómetros al poniente de la Ciudad de México. El objeto es describir la forma cómo se configura un sistema de relaciones a partir de dramas cotidianos que se justifican por la construcción diaria, por parte de los ambulantes, de autoconstruirse un trabajo en el espacio público; el contrato social se observa, empíricamente, mediante el despliegue de teatralizaciones (performances), para establecer los vínculos y relaciones sociales, observables a través de mediaciones conceptuales como la discrecionalidad y la corrupción; en dicho contrato social se naturaliza la desigual que define, sociológicamente, las posibles relaciones según posiciones jerárquicas en la estructura social; y se resalta el conflicto como elemento de gestión estructurante para las relaciones sociales en estructuras de desigualdad.

Este contrato social, manifiesto en el entramado relacional local entre la autoridad y los trabajadores informales, y también entre estos, permite reconocer las causas de la reproducción de la informalidad en la medida que el contrato social es débil, es decir, el contexto en el que se despliega la informalidad del comercio callejero se caracteriza por poseer una norma institucionalizada opaca, no objetiva, fundada en la discrecionalidad y en la corrupción, lo que le da un papel activo a la agencia social en tanto todos los días, los informales, deben negociar e improvisar el proceso social - en un contrato social débil, la informalidad, aunque esté prohibida, cuenta con la predisposición, de todos los actores involucrados, para ser tolerada, pero de la misma forma, pero en el ámbito 
económico, esta tolerancia se apoya en otro reconocimiento, que el capitalismo no es capaz de proveer a todos de un trabajo formal-. La dialéctica de los temas tratados es compleja en la medida que el marco institucional, o sistema de relaciones, proporciona la imagen de estructuras dadas — reglas oficiales, permisos, trámites obligatorios para vender en la calle, higiene pública, etcétera-, contrario al planteamiento que refiere a la construcción cotidiana del trabajo, lo que remite más bien a procesos permanentes de construcción y negociación de lo social.

Resumiendo, el artículo centra la mirada en un lugar de comercio ambulante en la ciudad de Toluca. A partir de este universo empírico focaliza en los vínculos sociales, que se configuran a través de las interacciones entre actores sociales inmersos en débiles reglas de administración pública de la calle. Las preguntas teóricas se construyen desde una lectura empírica que resalta la teatralización cotidiana de la vida. Se trata de acceder a la configuración de lo social como una construcción permanente entre ambulantes y autoridades, a través de esta red de interdependencias, observable en las prácticas cotidianas del trabajo popular que es la informalidad para la venta de bienes, se pretende dar cuenta de la administración social del conflicto para hacer sociedad, en contextos de contratos sociales débiles.

La informalidad refiere, empíricamente, a todo tipo de actividad productiva, comercial o laboral que se lleva a cabo sin controles administrativos ni fiscales. El despliegue de este tipo de actividades, por parte de los ambulantes callejeros y para definirlo en función de nuestro objeto de análisis, se hace mediante la apropiación del espacio público. Esto no saca a la informalidad de los procesos que responden a la acumulación de capital, pero sí dan cuenta de una desventaja sistémica en la distribución de la riqueza (Bueno 2016:111). Si bien no sólo los pobres practican la informalidad (las profesiones la practican, hay negocios transnacionales que se fundan en contratos informales, etcétera), se puede afirmar que la articulación entre pobres y apropiación del espacio público para la venta callejera, si bien no es exclusiva representa un patrón característico de la informalidad de la pobreza, es decir, de los que acceden con mayores desventajas a la distribución de la riqueza. Se puede afirmar, así, que este tipo de actividades se consideran residuales frente a la lógica del trabajo formal, proyectado por el modelo capitalista fundado en el empleo y la ganancia y de cuya perspectiva se fundan las políticas urbanas para los espacios públicos de calidad, en los que no hay cabida para los ambulantes en tanto afectan el paisaje urbano; de ahí que estos espacios de venta callejera desde la informalidad, manifiesten el lado reverso del sistema asalariado (formal).

Esta dualidad conceptual la encontramos en el argumento de Hart (1973), quien separa la economía formal y la informal. Ambas prácticas son componentes de la acumulación capitalista (Alarcón, 2008), pero a este artículo interesa ver las formas de gobernabilidad que se establecen entre los actores que forman parte de estos escenarios públicos de 
comercio ambulante, es decir, se indaga en las formas que adquiere el contrato social en las interacciones entre informales y autoridades que es producto de las formas de gestión de la calle para auto procurarse un trabajo. De ahí que sirven, para este objetivo, los descubrimientos que De Soto hizo desde 1987, cuando resalta que para que sean exitosos este tipo de emprendimientos populares, requieren de redes de apoyo y complicidades con diferentes actores sociales. En el elogio de la informalidad que este autor hace, enfatiza la autogestión popular con los propios recursos, de ahí que encuentra en la lógica callejera la misma lógica neoliberal. Esta lectura se articula con la apropiación del espacio público como infraestructura para esos emprendimientos rústicos y populares. Se generan así los espacios tolerados (Bueno 2016:120) que establecen sus propias reglas mediante la discrecionalidad y la corrupción; se despliegan permisos orales pasando sobre los trámites formales, lo que deriva en la posibilidad de mantener $e l$ emprendimiento desde abajo, al tiempo que se generan las condiciones para mantener a los ambulantes en las posiciones más bajas de la jerarquía social. De ahí que el trabajo informal sea un fin buscado, construido y realizado, por la agencia, todos los días; el espacio público se considera legítimo apropiárselo - para trabajar, como indican los valores liberales-, lo que lleva a la emergencia de dramas cotidianos para gestionar esa posibilidad, donde el conflicto es la base estructurante de la gestión por trabajar y por apropiarse de un espacio urbano público. Construir las ocasiones para procurarse un trabajo (Palma 1988), indica que el conflicto será la cualidad de gestión de la vida de los sectores populares que participan de estas actividades. En este sentido, sigo la vieja hipótesis de Polanyi (1976) cuando argumenta que toda actividad económica se asienta en relaciones sociales más amplias que incorporan las culturales y las institucionales.

\section{METODOLOGÍA}

El comercio ambulante del que trata este trabajo se despliega en un espacio público, más específicamente en la calle. Hay dos formas sociales de desplegar el trabajo informal: 1) los que se instalan en determinado lugar mediante una estrategia organizada, construyendo pasajes o mercados de informalidad y obligando el despliegue de una red de relaciones políticas clientelares que se convierten, junto con la propia organización, en una coraza protectora de los intereses gremiales; 2) aquellos que de forma familiar/ individual escogen un lugar para colocar su puesto, mediante arreglos de trato personal, con una red social austera - permisos de palabra, permisos dados por conocidos, protecciones ineficaces-, pero funcional. En este trabajo enfocaré en estos últimos. Ambos refieren a sectores de escasos recursos y obligan a un tipo de organización básica que funciona para la gestión permanente del conflicto, pues sabedores de que la informalidad y la apropiación del espacio público está normada, se considera que la autoridad es flexible y que "la ley se puede negociar" mediante arreglos cómplices y corruptas relaciones. 
El método utilizado fue el de observar un conflicto entre comerciantes y haberle dado relativo seguimiento. Se trata de un ejercicio de observación, desde el cual, al seguirlo en su propia trama, se fueron mostrando las interacciones, a partir de las cuáles fui construyendo el sistema de relaciones con que cuentan y hacen uso los trabajadores callejeros. Es la trama y desenlace de dicho conflicto lo que me permitió ver el sistema de relaciones que se funda entre la autoridad y los comerciantes ambulantes de familias individuales. Debo decir que en buena medida construí este sistema de relaciones en el contexto de una oportunidad inesperada, pues tuve la ocasión imperativa de recoger a los hijos de una amiga a la salida de su escuela, en las cercanías del centro/sur de la ciudad de Toluca, de julio a diciembre del año 2016. Fue allí que primero me acostumbre a observar las formas de desplegar los puestos, luego las actividades comerciales, para inesperadamente testificar el conflicto y las formas de resolverlo. Esta suerte azarosa me llevó a pensar en el conflicto como marca fundamental de la gestión de la calle para estos ambulantes, luego articulé estos dramas con planteamientos teóricos para llegar a la conclusión de que estaba en presencia de las formas cómo los pobres se construyen las ocasiones para un trabajo. Fueros esas dos razones las que me motivaron a darle seguimiento al conflicto callejero. Con base en estas observaciones pude descubrir el sistema de relaciones que se configura a partir de la gestión conflictiva del trabajo y la apropiación de la calle.

Buena parte del trabajo lo realicé con la observación (el texto está escrito como si se tratara de un observador distante), pero otra parte la complementé con entrevistas improvisadas a los actores de este drama empírico. El aporte del trabajo radica en eso, en que a partir del drama que implica la gestión popular por el trabajo en el espacio público, se configuran las observaciones que afirman que el capitalismo es un productor de pobreza, que la gente pobre se gana la vida con estrategias diversas, entre ellas la venta ambulante de bienes, siendo la calle un espacio susceptible de apropiación con los propios recursos populares, y que en esta trama, se puede construir una urdimbre de relaciones sociales entre los propios ambulantes, y entre aquellos y los actores administrativos en marcos institucionales que se ejecutan con elasticidades diferenciadas ${ }^{l}$, es decir, con distintas cantidades de tolerancia.

El resultado relevante es que a partir de una lectura etnográfica de un espacio público de venta informal, se describen las formas como los ambulantes dramatizan su cotidianidad y la convierten en acción social (con intención e inversión de esfuerzo) para procurarse

1. Elasticidades diferenciadas significa que se implementa la norma fuerte en contextos de políticas públicas que buscan construir espacios públicos de calidad o la gentrificación de algunos barrios; pero en casos en que no hay políticas de este tipo, la tolerancia a la apropiación del espacio público es amplia. La elasticidad depende en buena medida de las políticas gubernamentales que afectan cierto sector del espacio urbano. 
un trabajo, apropiándose de la calle, y abriendo el abanico de relaciones que contribuyen a la construcción de un sistema de relaciones.

\section{CRÓNICA DE UN DRAMA QUE HACE EXPLOTAR UN SISTEMA DE VÍNCULOS SOCIALES}

La ciudad de Toluca contiene una cantidad significativa de comerciantes ambulantes que han tomado algunos lugares de ciertas calles para expender sus productos. Si bien es cierto que esta ciudad de Toluca cuenta con 819.561 habitantes de 1.918 .798 con su zona metropolitana (INEGI, 2010) ${ }^{2}$, no cuenta en la actualidad, y no ha contado desde hace años, con un programa de venta global de la ciudad que la obligue a una política de recuperación de espacios de calidad ${ }^{3}$ para el turismo, la movilidad, espacios verdes, o programa de gentrificación alguno. Cuenta con un Bando Municipal que regula el uso de la calle, donde se enuncia la prohibición de la venta callejera en todo el municipio (lo cual ilustra la flexibilidad o debilidad del contrato social).

El lugar específico que refiere este artículo es en las afueras de una escuela. Existen allí innumerables puestos de distintos productos. Una señora expende antojitos mexicanos, dice que el director no la dejó colocarse exactamente frente a la entrada, pero que desde ese sitio en que se encuentra alcanza a captar cierta demanda de jóvenes y niños (as) estudiantes. Las relaciones entre el director de la escuela y los ambulantes generan permisos de palabra, como si la calle inmediata a la escuela fuera patrimonio del director. Esta es una primer relación social que emerge en este universo social ${ }^{4}$. La hora de salida de dicha escuela convierte la calle en una muchedumbre de niños, niñas, padres y madres de familia y comerciantes ambulantes cuyas humanidades son contenidas por una cerca tubular, de metal, que impide lanzarlos a la avenida. La multitud de infantes de color gris, como es su uniforme, hace aparecer este momento como un hervidero de infantiles humanos. Afuera de la contención, la señora que vende papas fritas hace un esfuerzo por atender con diligencia; lo mismo hace el señor que vende congeladas; allá en la esquina, donde termina el enrejado, se encuentra un puesto de dulces, junto a

2. Los municipios que conforman esta metrópoli son, además de Toluca, los de Lerma, San Mateo Atenco, Metepec, Ocoyoacac, Zinacantepec, Xonacatlán, Almoloya de Juárez, Otzolotepec, Calimaya, Chapultepec, Mexicalzingo, Rayón, San Antonio la Isla y Tianguistenco (González, 2012).

3. Se estableció un programa de recuperación de espacios públicos para disminuir la delincuencia pero el criterio de su asignación terminó por ser más electorero a que atendiera la problemática de seguridad. 4. Lo mismo sucede con los restoranes y tiendas que se apropian del espacio inmediatamente a las afueras de sus establecimientos, colocando letreros o cubetas para resguardar (apropiarse), para ellos, el espacio público. 
él, otro que expende el mismo producto, luego uno de enchiladas y finalmente otro de tostadas 5 . La venta es concurrente y los niños compran, entre risas, gritos y empujones. Paulatinamente, la multitud se va dispersando y los puestos comienzan a quedar vacíos. La señora del primer puesto de dulces es oriunda de San Pablo Autopan, la del segundo, de San Buenaventura, dos pueblos de ascendencia indígena que están experimentado la conurbación a la zona metropolitana. La primera va a vender sola, a veces por la tarde llega su hermana a acompañarla. La señora del segundo puesto lleva a su hija y el esposo de ésta, quienes tienen un bebé, que también los acompaña. La señora del segundo puesto platica que tiene a su mamá muy enferma, comenta incluso que está a punto de morir, la del primer puesto lo lamenta y le expresa su condolencia. Después, aquella enfatiza en que no le alcanza para los gastos médicos, toda la familia mira con cierto desprecio a la del primer puesto que se limita a expresar un "lo siento". Luego viene una letanía de quejas que focalizan en el problema de vender lo mismo en el mismo lugar: se siente una molestia inesperada, incluso parece que un conflicto está latente; comienza diciendo que no se debería aceptar puestos de dulces en el mismo sitio, que eso es una deslealtad, termina proponiendo que la del primer puesto se vaya a otro sitio. La del primer puesto de dulces ríe con sorna, no puede creer que dicha propuesta se le esté haciendo por parte de una colega. Un chofer del servicio público se ha detenido en la avenida y descaradamente e importándole poco los pasajeros que transporta, pide un agua gaseosa y la bebe despacio, mientras platica y echa chistes con la señora del primer puesto de dulces; los pasajeros esperan, después de todo, es práctica normalizada hacerlo, por parte de los funcionarios de gobierno - los transportistas lo son en la medida de las concesiones del servicio que el gobierno les otorga-. ¿Cómo explicar que el chofer de una unidad de servicio de transporte público deje esperando al pasaje mientras satisface su sed particular? Lo público es invadido por las aspiraciones privadas, expresión de un contrato social débil.

Por la tarde, llega al lugar la hermana de la dueña del puesto vulnerabilizado. Se le comunica que la señora del otro puesto ha estado amenazando con expulsarla del lugar. Las competidoras ambulantes se voltean a ver con rencor. Se trata ahora de un pleito entre dos familias. Llega la noche, la del primer puesto va a dejar sus dulces, mesa y sillas, a un estacionamiento cercano, allí, el encargado le cuida el puesto; la señora del segundo puesto, lo guarda en otro estacionamiento cuyo dueño le cobra 120 pesos al mes ${ }^{6}$.

5. Las enchiladas y las tostadas son antojos mexicanos; las congeladas son dulces de hielo.

6. El que a una le cobren y a la otra no, es el resultado de la cercanía o amistad de las relaciones que cada familia tenga en particular. 
Al día siguiente, la señora del primer puesto llega más temprano y se instala. Va acompañada de su hermana. Ella tiene un hijo que estudia en dicha escuela, lo que la hace, además de vendedora, parte de la sociedad de padres de familia. La señora del segundo puesto llega media hora después y cuando se percata de que ya se encuentra instalado el primer puesto, comienza a endilgarles el status de personas avariciosas e insaciables. Las hermanas escuchan y se reservan sus comentarios, la señora insiste en que ellas deberían buscar otro lugar; el joven papá, se encuentra cargando al bebé quién empieza a llorar, la hija da gritos para atraer a la demanda, el ruido de los autobuses de transporte público y el smog que lanzan, hace que el espacio se llene de un tenso y espectacular estrés. Toda la familia se encuentra en la actividad, se trata de tres generaciones que venden con la aspiración ilusionista de la movilidad social. Una de las hermanas rompe su silencio diciendo que si alguien debe buscar otro sitio no son ellos, después le reprocha a su colega que es incorrecto traer a ese bebé a esta zona de smog y ruido, luego le lanza un reclamo al joven para que vaya a buscar trabajo, como si el ambulantaje no lo fuera, es decir, como si se le exigiera a él estar en el reverso de esta actividad, en el trabajo asalariado (formal). La señora se levanta y con el dedo, señalando, grita que ellos si tienen necesidad de trabajar porque está muriendo su madre; la hermana contesta que todos tenemos necesidad y que uno de ellos se debería ir a cuidar a la señora enferma, en vez de estar todos perdiendo el tiempo aquí, luego remata, "se ve que no tienen madre"; la señora del segundo puesto se acerca con la mirada vidriosa lanzando en voz alta un "con mi madre no te metas", al tiempo que avienta el primer manotazo, la hermana se sacude pero no cae, y desde abajo alcanza a atrapar el cabello de la primera; después de un instante, logran separarse y lanzan puños y palmas que golpean sus rostros o rebanan el aire, la hija de la señora quiere meterse al pleito pero la hermana de la contrincante se lo impide; el bebé llora con más fuerza, los camioneros de la avenida detienen su trayecto para ver el espectáculo, una multitud con morbosa curiosidad observa la pelea, entre ellos dos policías que se divierten. El joven yerno/esposo/padre quiere meterse a separar a las dos mujeres pues parece que su suegra está perdiendo, pero los hombres que se encuentran alrededor lo amenazan diciéndole que se trata de una "pelea limpia", además, impide que se meta de lleno a la contienda el hecho de que no sabe dónde colocar al bebé. El conflicto como condición para la gestión de hacerse un trabajo, para los pobres, puede derivar hacia la violencia directa. Las dos mujeres hacen una tregua en su pleito, la hermana de la del primer puesto le reclama: "la que se va a ir vas a ser tú"; la del segundo puesto le dice que en realidad se van a ir las interpeladas porque ella tiene un conocido que trabaja en un partido político, otra relación que emerge de este universo popular. No se trata de instituciones sino de conocidos que pueden arreglar los asuntos públicos, ese es el mensaje. 
La del primer puesto le dice a la otra que si quiere arreglar los asuntos con peleas que está dispuesta, luego reta al joven papá/esposo/yerno; entre groserías y humillaciones éste le contesta haciéndose para atrás. La multitud empieza a dispersarse y el tráfico de los autobuses y autos de la avenida recomienzan a circular en medio de los cláxones y el clamoroso llanto del bebé. Las dos mujeres se encuentran despeinadas y llevan en sus rostros las marcas de este conflicto transmutado en violencia. Las dos hermanas deciden mantenerse en el lugar permanentemente ante la posibilidad de perder esta fuente de ingresos ${ }^{7}$. Las dos familias atienden a cada una de las contrincantes limpiándoles los rasguños. Suena el teléfono de la del segundo puesto, empieza una conversación que termina en llanto, la señora sale corriendo del lugar y encarga el puesto a la pareja de jóvenes esposos; le acaban de avisar que llevaron a su madre de urgencia al hospital. Las miradas filosas continúan en este pequeño espacio urbano. Pasadas dos horas, la hermana se dirige a la entrada de la escuela, desea hablar con el director. Los esposos ven con desconfianza cómo le abren la puerta y logra entrar. Una vez con el director, le informa que asiste a la escuela su sobrino, hijo de la dependiente del primer puesto de dulces, luego le dice que los hijos de ella también estudiaron allí, el director los recuerda. Le platica el conflicto y las causas de esos rayones de cara con los que se presenta a la entrevista, el director le indica que la señora del segundo puesto no tiene derecho a instalarse allí, que la del primer puesto, o sea su hermana, puede hacerlo porque tiene un hijo estudiando en la escuela; surge aquí otra relación del sistema de relaciones, la discrecionalidad del permiso de palabra para legitimar el uso del espacio público. Luego el director le recomienda, aun y con su permiso de palabra y su argumento de legitimidad, ir al Ministerio Público y levantar un acta sobre los hechos. Ella sale de la escuela con arrogancia, sabe que ha conseguido dos cosas: el permiso de palabra —con disfraz de legitimidad - del director de la escuela para instalarse en el lugar y una ruta posible para defender su espacio de comercio ambulante frente a la autoridad. Llega diciendo a su hermana, en voz alta, que no hay de qué preocuparse. Los interpelados la escuchan. Estas relaciones indican que la gestión en conflicto es una marca que sigue permanentemente a las unidades familiares que se apropian de un espacio público para ejercer su precario trabajo.

La hermana deja el puesto y se dirige al Ministerio Público de la ciudad de Toluca donde levanta un acta. Quien la atiende le dice que le muestre los recibos de pago por el uso del suelo, ésta le indica que paga a un representante del municipio pero que éste no les da comprobante. Está confiada porque tampoco la del segundo puesto cuenta con ellos, aunque también paga. El representante del Ministerio continúa con el levantamiento

7. Esto implica, me comenta la señora, faltas a su trabajo como trabajadora doméstica o no asistir a las juntas de los programas gubernamentales del subsidio público, todas ellas fuentes diversas de su ingreso monetario. 
del acta y allí terminará el trámite. Esto muestra que la escasa institucionalidad genera las condiciones para el conflicto, pues todos deben hacerse del espacio público con sus propios medios. La señora se lleva todo el día en esta diligencia, recibe una copia del acta, una simple declaración de hechos. Las oficinas del Ministerio Público prometen que se presentarán en el lugar para calmar los ánimos, cosa que nunca sucede. Emergen aquí dos relaciones sociales del sistema: la relación con el pago de uso del suelo al representante del municipio; éste no les da recibo pero sí cobra, es un acto de corrupción con apariencia delincuencial, pues este cobro bien puede significar el pago de una cuota para no ser molestados por la burocracia municipal, una especie de pago por uso del suelo; la otra relación es con el Ministerio, una oficina que no pondrá orden en el uso del espacio público, pues no tiene competencia en ello. Desde la perspectiva oficial, las familias populares que se apropian del espacio público para trabajar no son objeto de justicia pues, como lo destaca Raphael en voz de una jurista, "el Ministerio Público es una institución que en México nació con el propósito de imponer control sobre los adversarios políticos y también sobre una ciudadanía rebelde y siempre dispuesta a negociar a partir de su propia desobediencia, por ello es que quién desempeña esta función no se entiende a sí mismo como defensor del pueblo, como abogado de las víctimas, y mucho menos como garante del debido proceso judicial" (Raphael 2015:113-114) ${ }^{8}$. Este pleito emergente ilustra el tipo de contrato social que se despliega en la relación de la autoridad con los ambulantes. Se observa que la justicia y la institucionalidad se negocian; y que la discrecionalidad y la corrupción se erigen como componentes de estas relaciones.

Así, le informó a su hermana que el acta estaba levantada. Mostraba la copia para que los vecinos comerciantes se dieran cuenta de la acción. Ellos pudieron distinguir los sellos institucionales que configuró al acta como un emblema o un símbolo de poder relacional, más no de justicia, y asumieron que habían perdido el pleito. Reconocieron la derrota en la convicción de que las adversarias tenían más conocidos en el entramado institucional que ellos, quiénes sólo poseían a un conocido de un partido político. Se configura así la debilidad del contrato social y de la institucionalidad. Emerge aquí no sólo la cuestión de que la justicia se negocia, sino la idea generalizada de que las redes sociales configuran mayores o menores oportunidades para adquirir justicia, lo que es lo mismo decir, para ganar pleitos y dirimir conflictos. Obviamente nadie supo más del Ministerio Público ni del partido político, pero sí se proyectó la débil malla o red social de poder con la que cuentan las familias pobres.

\footnotetext{
8. Este arquetipo se reproduce desde los tiempos de la Colonia, por ejemplo, el visitador Alonso Zorita decía que la ley en la Nueva España no representaba sino artilugios impuestos por los españoles a los indígenas, pues estos ni siquiera comprendían la clase de derecho y justicias que se enunciaban en dichas leyes (1942), por lo que se puede ver el origen colonial del uso de la ley que en buena medida configura el contrato social entre la autoridad y los vendedores ambulantes.
} 


\section{DEL PAISAJE URBANO AL PASAJE COMERCIAL URBANO}

La vida en las urbes proyecta siempre imaginarios entrecruzados que dan pistas para saber quiénes somos, pero más enfáticamente, deducciones de quiénes somos a partir de lo que hacemos, prueba infalible que ilustra, a grandes trazos, también lo que nos ocurre, lo que sufrimos o por lo menos las vicisitudes por las que atravesamos en nuestras vidas. Y es que, como dice Delgado (2007), lo urbano no es espacio físico o diseño arquitectónico planificado, es ante todo cultura, forma de vida, modo de ser, expresión de lo que nos ocurre en la vida, manifestado en las formas singulares de su apropiación. De ahí que en buena medida, se pueda afirmar que lo que sucede en ese recoveco urbano con la informalidad y sus relaciones sociales, sea un microcosmos de la sociedad en general, de la de Toluca y la mexicana en dos escalas.

Resumiendo. El eje articulador de este artículo es la apropiación del espacio urbano que hacen las familias para trabajar en el comercio ambulante, lugar desde el que se configura un sistema de relaciones. El universo de observación es un espacio público: las afueras de una escuela. Esta porción de calle es un paisaje hecho para la contemplación o el uso funcional para los estudiantes, que se transforma en un pasaje comercial, para seguir de manera heterodoxa, el programa de Walter Benjamin (2005), en la medida que hay productos que se ofertan, pues dicho espacio ha sido apropiado y significado por ciertos actores, precisamente aquellos oferentes de dulces o, aquellos comerciantes ambulantes, haciendo de la calle un pasaje de compra y venta de productos?

Tenemos así que hay espacios públicos - la calle - apropiados, en los que se cruzan sentidos normativos y formales - aunque débiles - con sentidos estratégicos para construir el trabajo y la vida que los pobres movilizan. Este tipo de apropiaciones del espacio establece vínculos sociales diversos entre actores sociales, entre ellos destacan los que dan permisos de palabra y las autoridades, configurando ideas subjetivas sobre lo que es lo público. Las relaciones con actores diferenciados generan también poderes diferenciados. Estos actores vinculados van desde el director de escuela; el representante del Ayuntamiento que mediante la discrecionalidad y la corrupción terminan por construir espacios públicos tolerados para los ambulantes; las relaciones negociadas y violentas con los otros comerciantes ambulantes; las relaciones comerciales con los

\footnotetext{
9. Seguir ortodoxamente el programa de Bejamin impediría construir a los emprendimientos populares como pasajes comerciales. Su programa hallevado a reflexionar el estudio de los malls o centros comerciales, espacios consagrados a la compra de bienes sin intromisiones inseguras y presencia de higiene. Aquí quiero resaltar su programa de manera más bien heterodoxa, diciendo que los emprendimientos populares también conforman oferta de bienes, y al hacerlo, transforman el espacio público en escaparates austeros que, a su vez, terminan configurando demandas. El mecanismo es transformar el espacio público en un mercado emergente.
} 
clientes cautivos y los esporádicos. En este sentido, se puede decir que la vida social en los espacios públicos singulares de las metrópolis no se caracterizan por estar ordenados, sino por estar sin cesar ordenándose (Delgado 2007:90). Las formas de apropiación del espacio urbano parecen transitar en una tensión permanente entre ser simples productos de la planificación urbana o lugares con sentido cultural, lo que los articula son la negociación para el despliegue de la vida precaria o popular con las rigideces institucionales que proclaman siempre el control de lo público, mediante cualquier artilugio, implique la norma o la corrupción.

De esta forma, el espacio urbano apropiado por los ambulantes, permanece inserto en un sistema de relaciones que proyectan un débil contrato social, cuya debilidad se explica por la existencia de espacios tolerados que derivan de la discrecionalidad, de la autoridad, para transformar los permisos oficiales en permisos de palabra; y en la gestión del conflicto como relación necesaria para mantener la apropiación del espacio público para la venta de productos. En esta debilidad institucional se configura la conciencia de que la calle es de todos, y al serlo, cualquiera puede apropiársela y cualquiera puede dar permisos de palabra diferenciados según su posición en la estructura social y espacial. Se configuran así pequeños poderes estructurados en función de la red de conocidos que cada actor posee, más no de las reglas institucionales que explícitamente orientan las acciones —establecidas de antemano en el Bando Municipal-.

Si la legitimidad sentida para apropiarse del espacio público existe pese a que la normatividad lo prohíbe, es porque la corrupción forma parte del sistema social de relaciones; si hay puestos ambulantes colocados en mejores posiciones que otros, es porque el sistema de relaciones jerarquiza en función del tipo de redes de conocidos que se poseen para hacer valer esas pequeñas diferencias a favor. De ahí que las reglas sociales se construyan todos los días, y en este hacerse permanente se da la posibilidad de la reproducción del sistema de relaciones sociales en su conjunto. Afirmo que la configuración de las normas sociales e institucionales del contrato social de la sociedad mexicana se sustenta en un débil contrato social que, por dicha razón, obliga y permite a las personas a buscar la manera de construirlo con sus propios medios. Este me parece es el mensaje social de este caso de estudio.

Estos espacios son relevantes por sí mismos - el ambulantaje, me parece, siempre será un tema actual- porque en ellos se proyectan relaciones sociales generales que explican la perpetuación de los pobres. Metodológicamente dirijo la mirada a un punto específico de la metrópoli y lo conceptualizo como un espacio que, al generar prácticas y narrativas, es un procesador de vínculos sociales. En él se generan una serie de actos de cotidianidad en situaciones permanentes de no equilibrio, pues las relaciones de negociación por el espacio público movilizan estrategias y definen el tipo de relaciones que legitiman los actos que se suceden cotidianamente. En este sentido, vale la afirmación 
de que lo social siempre está por hacerse e implica la negociación permanente entre actores sociales. De ahí que el apropiarse de un espacio público sea adaptarse a un lugar mediante la competencia, la indiferencia, la amistad o la lucha permanente. Apropiarse de un espacio público no significa sino la adaptación a un sistema de relaciones ${ }^{10}$ dados, que se interpretan en sus trazos más generales pero desde los cuales se sostienen las posibilidades de relaciones con otros actores. Así, en situaciones institucionales débiles, como es el caso de este contrato social entre la autoridad y los pobres; la indiferencia, la negociación, la competencia, la corrupción y las redes sociales tienen cualidades estructurantes de las relaciones sociales, parafraseando a Delgado (2007).

\section{LA INFORMALIDAD COMO CONSTRUCTORA DE ESPACIOS DE ESPERANZA}

Una pregunta de sumo interés es la de valorar las formas en que el capitalismo genera pobres como consecuencia estructural del factor distributivo de la riqueza. El planteamiento es interesante en la medida que los pobres bien pueden ser una invención de las relaciones sociales capitalistas en tanto que éstas buscan la dependencia completa de los individuos hacia el dinero (Gual 1996). Ya la ecología cultural nos enseñó, desde la década de los setenta, que la pobreza es una cuestión de perspectiva (Steward 2014) ${ }^{11}$, pero fundamentalmente indica que ésta se produce desde el capitalismo en la medida que este sistema no puede integrar a la totalidad de los individuos en roles sociales, y menos en expectativas de conformidad económico/estructural, como sugería el Parsons más funcionalista (1961).

La emergencia permanente de pobres, forma parte del sistema de relaciones que el capitalismo crea. Esta escalada de pobreza se genera por el propio funcionamiento del capital que requiere acumular mediante la apropiación del patrimonio de las personas; la primera escalada ya el propio Marx nos la relató en la acumulación originaria (1986), pero es un hecho que en la actualidad esta escalada acumulativa por desposesión se expresa en la voraz actividad de los bancos — que buscan por todos los medios enlazar

10. El sentido de adaptación generalmente se asigna a un ecosistema, acá quiero hacer énfasis en la adaptación a un sistema de relaciones (que implican mapas mentales sobre su funcionamiento, sus peligros y las posibles soluciones a los conflictos que engendre).

11. Para la ecología cultural cada pueblo integra en sus modos de vida las riquezas colectivas relativas en la medida que no hay una regla estandarizada para medir grados de pobreza y riqueza. En ese sentido, una comunidad que se alimenta con semillas sin necesidad de mucha proteína es rica, sólo cuando se somete a la valoración eurocéntrica capitalista se convierte en pobre. En este sentido la pobreza es una invención del capitalismo que desea integrar a todos a las relaciones sociales basadas en el dinero. Una sociedad de relaciones monetarias genera un tipo social cuyo contrato es el civil, parafraseando a Simmel (2003). 
a los individuos mediante créditos que serán liquidados en el trayecto de toda una vida - y en la emergencia de negocios ilícitos y lícitos que arrebatan a los campesinos de sus propiedades últimas (Harvey 2005), erosionando con ello incluso las formas comunitarias del tejido social, lo que se ha llamado la etnofagia (Díaz Polanco 2007), pero también mediante la ideología del consumo que disfraza los logros y la realización de la vida mediante el consumismo irreflexivo (Leonard 2013).

Ante esta situación de violencia estructural, para seguir el esquema de Galtung (2003), los pobres establecen estrategias para subsistir en un mundo que estructuralmente está cerrado para ellos. Entre esas estrategias se encuentran la emigración y la informalidad comercial, pues ambas acciones son una reacción que “... responde a procesos selectivos de acumulación de capital que dan cuenta de una desventaja sistémica en la distribución de la riqueza, produciendo espacios de esperanza" (Bueno 2016:111). Y es que de algún modo las respuestas individuales - familiares - a las violencias estructurales que se generan por la misma lógica de acumulación del capital, se encuentran sometidas a los imperativos de realización de la vida, en claves axiológicas - dirigidas al desarrollo personal, el bienestar, el éxito, la felicidad, etcétera-, mediante la persuasión y seducción al pleno consumo. De ahí que los grupos populares se encuentren siempre a la búsqueda de esta ilusoria realización.

Así, los sectores con menores recursos, y en medio de un sistema capitalista que los excluye del empleo asalariado - o cuando lo genera lo hace con salarios precarios, como es el caso de muchas regiones del llamado tercer mundo, entre ellas México-, optan por abastecerse con sus propios medios de subsistencia con recursos propios. Así, las relaciones económicas y políticas (ambas informales en la medida que se componen de tratos por abajo o por encima de las reglas institucionales), configuran un contrato social débil. En este sentido, y siguiendo la hipótesis de Carmen Bueno (2016), se puede decir que la informalidad no es un factor marginal y subalterno al capitalismo, es sobre todo un elemento estructural del capitalismo dependiente (Tokman 1978). De esta forma, se puede agregar que la informalidad encuentra mejores condiciones para su despliegue en situaciones donde la reglamentación está permanentemente a debate o negociación, dadas sus cualidades opacas y ambiguas que los operadores de la norma establecen con los pobres.

Estos grupos populares combinan una serie de estrategias familiares que incluyen el trabajo del comercio informal con el empleo eventual (como son la construcción, el trabajo doméstico, la agricultura minifundista, la recolección y la inscripción a programas del subsidio público). Las estrategias familiares de subsistencia promueven redes sociales primarias que movilizan al conjunto de familiares en una estrategia de subsistencia colectiva (Salazar 1999). Ahora bien, pese a que la informalidad sea resultado estructural del capitalismo, ésta se encuentra siempre en constante lucha con 
los establecimientos fijos, pues estos generan contra discursos que implican el argumento de la competencia no legítima; además de la deslealtad por cuestiones impositivas. La informalidad se convierte, así, en una actividad que encuentra al conflicto como la marca estructurante de su gestión cotidiana. En este sentido, el conflicto como gestión resulta de encontrar una opción de subsistencia frente a la violencia estructural que el capitalismo crea. Los actores llamados "formales", que se aglutinan en los representantes del mercado - empresarios-y del Estado - gobiernos, partidos políticos-, realizan una lucha feroz contra los llamados "informales". En estas negociaciones políticas por el espacio, el conflicto se enarbola como el método central de dichas gestiones. Este conflicto se gestiona mediante las alianzas con distintos actores de poder - partidos, directores de escuelas, padres de iglesias, funcionarios de distintos niveles de gobierno, etcétera-. De esta forma el emprendimiento con autoempleo precario que emana de las estrategias de supervivencia desplegadas por las familias populares, significa apropiarse del espacio público bajo esquemas de violencia, dados los débiles lazos políticos que estos grupos poseen y el débil contrato social que termina por no regular ni sus acciones ni las de la autoridad. Lo que se cristaliza de este entramado de relaciones es, al final de cuentas, la administración política del uso de la calle, entramado relacional en el que se ven inmiscuidas las autoridades y los comerciantes ambulantes, estando en medio de estos, el drama permanente de la resolución de conflictos.

Así, cuando los grupos populares se apropian de un espacio público, convierten esas porciones de calles en "espacios tolerados" por parte de los actores poderosos, los cuales, como menciona Carmen Bueno (2016), se encuentran mediados por cuotas monetarias exigidas por burócratas que han impuesto sus propias reglas del juego y que, por lo tanto, colocan a estos vendedores con pocos márgenes de negociación, por lo que la disputa por el espacio público se debe hacer, a veces y en casos en que la eslasticidad de las tolerancias llega al límite, mediante la violencia directa entre los mismos comerciantes, como se ilustra en este caso y como en ocasiones lo muestran los medios de comunicación en que las batallas campales entre ambulantes y policías se llevan la nota periodística. Así, se puede concluir que el bien escaso por el que luchan estas unidades familiares es precisamente el trabajo, pues en cada día se disputa la posibilidad de ejercerlo, cada día se negocian las formas de acomodamiento del puesto ambulante en el sitio de siempre. El problema de esta gestión en conflicto, es que las reglas del juego se manifiestan como dadas o hechas, cuando en realidad son ambiguas $-\mathrm{y}$ se utilizan a discreción-, allí radica la dialéctica entre la estructura y la agencia, en que lo dado - la norma- es un "fantasma" que obliga a reconstruirse a diario, en que la institucionalidad es débil, por lo que hay que rehacerla permanentemente. Estos componentes teóricos tienen una forma empírica. Su expresión son las formas de dramatización que se convierten en acción social para gestionar el trabajo de todos los días. 
Se debe decir que la separación tajante entre formalidad e informalidad es un artificio (metodológico, político, policial, tributario, etcétera), pues ambos tipos de actividades son producto de las relaciones sociales que genera la forma de acumulación capitalista. El trabajo precario es el resultado de la desposesión — generadora de migración del campo a la ciudad, pero ahora manifiesta incluso de forma internacional,-, con la que funciona el capitalismo, aunque posteriormente se criminalice a los trabajadores precarios desde las estructuras del mercado y del Estado. De esta manera, la violencia estructural produce pobres y estos se ven obligados al emprendimiento precario, lo que significa crear las condiciones para trabajar, en un despliegue de dramas cotidianos, pues estos dramas provocan las condiciones necesarias para poseer un trabajo.

\section{CONCLUSIONES}

La dialéctica entre ciudad y ambulantaje fue el principio de análisis en este trabajo, es decir, la ciudad como espacio transformado en pasaje comercial popular por la venta de productos desde las familias individuales. Estos ambulantes organizan el comercio informal como una parte de varias actividades económicas que en su conjunto contribuyen a la subsistencia. Entre las distintas modalidades de labor están el trabajo doméstico - las mujeres como trabajadoras domésticas y los hombres como jardineros, vigilantes, choferes o albañiles-; la inscripción en programas de subsidio público que asignan despensas o dinero; la recolección de frutos, verduras y distintos tipos de pescados e insectos que se encuentran en las orillas de la ciudad. De ahí que la venta de productos de manera informal sea una de las varias actividades de subsistencia que movilizan estas familias. La suma de estas actividades representa la construcción permanente de las ocasiones para poder trabajar. Se trata de un agregado de actividades cuya meta es lograr la subsistencia día a día, es decir, se trata de gestionar conflictivamente la oportunidad cotidiana para trabajar. El ambulantaje trata de aprovechar la arquitectura planificada de un lugar urbano para transformarlo en un eventual pasaje comercial popular. Se despliega así una resignificación de la ciudad planificada en la medida que se destina su funcionalidad original a otro tipo de actividades, en este caso para la venta.

Un criterio para construir las ocasiones para el trabajo, es la posibilidad de conseguir un permiso de palabra. Podemos deducir que si se van a instalar en las afueras de una escuela, el permiso se adquiere con el director; si afuera de una iglesia con el sacerdote; si afuera de una tienda con el dueño del establecimiento. Este permiso implica siempre la negociación. Pero sucede que los permisos se piden siempre a personas a las que se les conoce - "se trata del director de la escuela en la que va mi hijo" o "se trata del cura a quien mi madre le hace la limpieza en su casa", dicen dos informantes-. Estos "permisos de palabra" son producto de la débil red social de los comerciantes ambulantes. Pero 
a la vez muestra la imagen que implica una predisposición a la patrimonialización del espacio público, lo que le da legitimidad a su uso y apropiación ${ }^{12}$.

Posteriormente llega el representante del municipio con la misión de cobrar uso del suelo. Dicen los informantes que generalmente se identifica de palabra y sólo cuando lo obligan a mostrar sus credenciales le hacen el pago. Los procedimientos parecen una especie de protección relativa ante la escalada de los controles que el municipio pretende hacer. La discrecionalidad y la corrupción son los componentes más explícitos de esta relación. En lo que respecta a las instituciones encargadas de aplicar las normas, parece que ésta se orienta políticamente y sólo se implementa a una ciudadanía desobediente, lo que genera una disposición permanente para negociar las reglas del juego social: esto da por resultado lo que llamo la administración pública de la calle. Asistimos a contextos en que las reglas del juego se construyen día a día (por eso la discrecionalidad y la corrupción son partes estructurales de este sistema de relaciones). Desde este recoveco urbano se prefiguran, para después proyectarse, las reglas generales del entramado social, es decir, de la institucionalidad social o el contrato público social.

No se trata de un edificio institucional neutral, pues las reglas del juego se negocian todos los días; el contrato social no es civil, pues los permisos de particulares hechos de palabra y discrecionales son los que rigen; no se trata de una distribución justa del espacio público -ni del ingreso-, pues éste se disputa hasta llegar a los golpes. Este es el contrato social sobre el que se erige la relación entre las autoridades que cuidan y regulan el espacio público y los pobres que todos los días se procuran las ocasiones para tener trabajo.

De esta forma, este artículo mostróla trama cotidiana en que los informales interaccionan con sus pares ambulantes y con distintos niveles de autoridades; todas estas relaciones caracterizadas por la gestión en conflicto. Se puede decir que el valor de este artículo es describir la acción social específica de un mundo estructural que produce pobres, personas que se ganan la vida diversificando estrategias múltiples, siendo el trabajo informal una de ellas, lo que hace legítimo apropiarse del espacio público, para luego trenzar una urdimbre de relaciones entre ellos y los actores administrativos, relaciones en que el conflicto es la base de la gestión popular, pues el contexto se define por una debilidad institucional.

12. Una analogía del sistema político mexicano es la acción de hacer campañas políticas con la presunción firmada ante notario, es decir, la acción de hacer valer la promesa de obras públicas como si fueran patrimonios de los candidatos/gobernantes (Reyes, 2014). 


\section{BIBLIOGRAFÍA}

Alarcón, Sandra. (2008). El tianguis global, U. Iberoamericana, México.

Benjamin, Walter. (2005). Libro de los pasajes, Akal, Madrid.

Bueno, Carmen. (2016). Configuraciones productivas en la globalización. Trayectorias a la mexicana, Universidad Iberoamericana, México.

Delgado, Manuel. (2007). Sociedades movedizas, pasos hacia una antropología de las calles, Anagrama, Barcelona.

De Soto, Hernando. (1987). El otro sendero, la revolución informal, Diana, México.

Díaz Polanco, Héctor. (2007). Elogio de la diversidad, globalización, multiculturalismo y etnofagia. Siglo XXI, México.

Galtung, Johan. (2003). Paz por medios pacíficos: paz y conflicto, desarrollo y civilización, Bakeaz, Madrid.

Gual, J. (1996). El reto social de crear empleo. Combatiendo el paro en Europa, Ariel, España.

González Ortiz, Felipe. (2012). Megalópoli y cultura, del ritual indígena al performance urbano, Porrúa, UAEMex, México.

Hart, K. (1973). "Informal Income Opportunities and Urban Employment in Modern Ghana”, en Journal of Modern African Studies, núm. 11. USA.

Harvey, David. (2005). El nuevo imperialismo, acumulación por desposesión, CLACSO, Buenos Aires.

INEGI. (2010). Censo nacional de población y vivienda, México.

Leonard, Annie. (2013). La historia de las cosas. De cómo nuestra obsesión por las cosas está destruyendo el planeta, nuestras comunidades y nuestra salud, y una visión de cambio, FCE, México.

Marx, Karl. (1986). El capital, tomo I, FCE, México.

Palma, D. (1988). "la informalidad, lo popular y el cambio social”, en Cuadernos Desco, Perú, núm. 8.

Parsons, Talcott. (1961). La estructura de la acción social, Guadarrama, Madrid.

Polanyi, Karl. (1976). “El sistema económico como proceso institucionalizado”, en Antropología y economía, Maurice Godelier (compilador), Anagrama, España.

Raphael, Ricardo. (2015). Mirreynato, la otra desigualdad, Booket, México.

Reyes Rojo, Griselda. (2014). Construcción social de la ciudadanía en el marco de la campaña Compromisos por México firmados ante notario público en Santa María 
Nativitas, Jiquipilco (2009-2010), Tesis de maestría de El Colegio Mexiquense, Zinacantepec,. México.

Salazar Cruz, C. (1999). Espacio y vida cotidiana en la ciudad de México, El Colegio de México, México.

Simmel, Georg. (2003). La filosofía del dinero, Comares, Madrid.

Steward, Julian. (2014). Teoría del cambio cultural, CIESAS, UAM-I, Universidad Iberoamericana, México.

Tokman, V. (1978). "An Exploration into the Nature of Informal-formal Sector Relationship", en The Urban Informal Sector: Critical Perspectives, GB: Word Development, sep-oct, Vol. 6.

Zorita, Alonso de. (1942). Los señores de la Nueva España, Imprenta universitaria, México. 